\title{
Determinants of smokeless tobacco use and prevalence among Sudanese adolescents
}

\author{
Mohammed Othman $^{1 *}$ (D), Nik Daliana Nik Farid ${ }^{1}$, Nasrin Aghamohammadi² and Mahmoud Danaee ${ }^{1}$
}

\begin{abstract}
Background: Smokeless tobacco is a part of social and cultural life in Sudan. The affordability and availability of this kind of tobacco make it a fundamental issue in adolescents. The aim of this study is to investigate the extent of the use of smokeless tobacco in adolescents and its determinants.

Methods: A school-based cross-sectional study was conducted in Khartoum state in Sudan. The study targeted male and female adolescents in secondary schools. A total of 3387 students from public and private schools participated in the study. Multistage random sampling was used to select the participants. The Arabic version questionnaire from the Global Youth Tobacco Survey (GYTS) was utilised to collect the data from the participants.

Results: Among the participants, 57.3\% were females and $42.7 \%$ were males. Students from private and public schools were 48.4 and $51.6 \%$, respectively. The overall prevalence of those who had ever used smokeless tobacco was $7.6 \%$, in which the prevalence among male students was $11.0 \%$ while among females was $5.0 \%$. The determinant factors were male gender (OR $1.53 \mathrm{Cl}$ 95\% 1.03-2.28), family structure (OR $1.52 \mathrm{Cl}$ 95\% 1.03-2.23), exposure to second-hand smoke at home (OR $1.60 \mathrm{Cl} 95 \%$ 1.11-2.31), friends smoking cigarettes (OR $1.78 \mathrm{Cl}$ 95\% 1.22-2.60), lack of restriction of selling tobacco to minors (OR $1.73 \mathrm{Cl} 95 \%$ 1.25-2.39), promotion of smokeless tobacco (OR 2.12 Cl 95\% 1.20-3.72) and low self-efficacy (OR $7.47 \mathrm{Cl} 95 \%$ 4.45-12.52).

Conclusion: A comprehensive prevention programme that enforces the prohibition of the promotion of smokeless tobacco and the selling of smokeless tobacco to minors is crucial. Moreover, the prevention programme should enhance adolescents' self-efficacy.
\end{abstract}

Keywords: Adolescent, Smokeless tobacco, Sudan, Toombak, Urban health

\section{Background}

Smokeless tobacco is any kind of tobacco that is consumed through mouth or nose without any burning. Chewing and dipping (sucking) are the most prominent forms of using oral smokeless tobacco [1]. Different types of smokeless tobaccos are available according to their plant species, nicotine concentration and additives.

\footnotetext{
* Correspondence: alshaikh_moh@yahoo.co.uk

'Department of Social and Preventive Medicine, Faculty of Medicine, University of Malaya, Kuala Lumpur, Malaysia

Full list of author information is available at the end of the article
}

The most prevalent type of smokeless tobacco in Sudan is toombak which was introduced approximately 400 years ago [2]. Toombak is planted, manufactured and produced locally. It is prepared from dried leaves of Nicotiana rustica that are mixed with natron (sodium bicarbonate) solution. The mixture is fermented for $24 \mathrm{~h}$ before use $[1,3]$. Nicotiana rustica contains up to $18 \%$ nicotine, which is more than Nicotiana tabacum that consists 0.5 to $9 \%$ nicotine [4].

Toombak dipping is practiced by taking a small portion from the toombak bag, putting it in the palm of the

(C) The Author(s). 2021 Open Access This article is licensed under a Creative Commons Attribution 4.0 International License, which permits use, sharing, adaptation, distribution and reproduction in any medium or format, as long as you give appropriate credit to the original author(s) and the source, provide a link to the Creative Commons licence, and indicate if changes were made. The images or other third party material in this article are included in the article's Creative Commons licence, unless indicated otherwise in a credit line to the material. If material is not included in the article's Creative Commons licence and your intended use is not permitted by statutory regulation or exceeds the permitted use, you will need to obtain permission directly from the copyright holder. To view a copy of this licence, visit http://creativecommons.org/licenses/by/4.0/ The Creative Commons Public Domain Dedication waiver (http://creativecommons.org/publicdomain/zero/1.0/) applies to the data made available in this article, unless otherwise stated in a credit line to the data. 
other hand to manipulate until it becomes a round solid mass. This mass is called saffa and it is weighted approximately about $10 \mathrm{~g}$ [3]. Saffa is mainly placed in three sites within the mouth; either between the gum and lip or between the cheek and lip or on the floor of the mouth [3]. It is left to absorb slowly for up to $1 \mathrm{~h}$ or until it becomes bland; however, an average of a saffa dipping is $10-15 \mathrm{~min}$ [3]. Adolescent choose to make a small saffa and dip it between the upper lip and gum, thus, it is unnoticeable and easily hidden [3].

Natron is added to toombak to homogenise the powder to have an alkaline effect which increases the $\mathrm{pH}$ to a range of 11.0-11.8. A high level of $\mathrm{pH}$ in tobacco products increases the absorption of nicotine; hence it increases its activity. Nicotine concentration in toombak, used in Sudan is $32.2-102.4 \mathrm{mg} / \mathrm{g}$, which is two times higher than smokeless tobacco (snuff) used in the USA and five times higher than the concentration of nicotine used in smokeless tobacco (snus) in Sweden [3]. Thus, toombak is highly addictive and cannot be resisted [3].

Additionally, many types of tobacco N-nitrosamines such as $\mathrm{N}$-nitrosonornicotine (NNN), 4-(methylnitrosamino)-1-(3-pyridyl)-1-butanone (NNK),N-nitrosoanatabine (NAT) and N0-nitrosoanabasine (NAB) are quantified in high levels in toombak products and the saliva of toombak users. The level of $\mathrm{N}$-nitrosamines in toombak is 100 folds higher than thst found in Swedish snus, and this can be attributed partially to the use of Nicotiana rustica plants, the fermentation process of toombak in high temperatures, prolonged storage and contamination during the process $[2,5]$.

Toombak usage was associated with oral cancer especially at the site where saffa was placed, and this was a result of a high level of N-nitrosamines in toombak. In Sudan, it was documented that the odds ratio of lip cancer in toombak users was OR 7.3(4.3-12.4) and the odds ratio of buccal and mouth floor cancer was OR 3.9 (2.95.3) [3]. Even more, the odds ratio of lip cancer increased in the long term for toombak users to reach OR 73.0 (9.8-542.2) [3]. This means that it has a dose-response relationship [3]. Furthermore, the use of toombak was associated with tumours of the salivary glands [6].

The prevalence of those who ever used toombak among 14-17-year-old Sudanese was 1.7\%. However, this percentage increased sharply to $11.3 \%$ in $18-19$ year-olds [2]. In 2010, among Sudanese secondary school students, the percentage of those who had tried toombak was $8.1 \%$ and that for the current users was $3.5 \%$. Whereas, in 2014 GYT survey, the prevalence increased to reach $13.2 \%$ for those who had tried toombak and the percentage of current users was 4.9\% [7]. However, in 2017 , the prevalence of those who had tried toombak decreased to $10.9 \%$ [8]. In Sweden, smokeless tobacco is called snus and it was reported that the percentage of those who ever used snus among Swedish students in the 9 th grade was $54.6 \%$ for males and $32.3 \%$ for females [9].While the prevalence of smokeless tobacco and betel quid in Pakistani secondary school students was 42.6\% [10]. In India, the chewing tobacco (Gutka) percentage was $10.8 \%$ among the sixth and eighth grade students in Delhi and Chennai [11].

A few studies in Sudan have addressed the issue of smokeless tobacco use in adolescents. Therefore, there is insufficient information on its use and its determinants in Sudan. None of the studies in Sudan have linked the family structure, allowance, grade, or academic performance with smokeless tobacco use and only one study has addressed the usage of smokeless tobacco in public and private schools.

Developed countries have advanced surveillance system that can spot and monitor tobacco use in adolescence. However, most of the developing countries do not have a system in place to monitor thus, tobaccorelated problems may be underestimated [12]. In Sudan, one-fifth of the population is adolescents who are under the age of 19 [13]. Therefore, health concerns and any matters that affect adolescents' health should be investigated and addressed. However, tobacco use in adolescence is seen as a less priority. Meanwhile tobacco is a major cause of preventable deaths as many users start consuming tobacco in early adolescence, which increases their risk because of the longer duration of tobacco use [14]. It is worth mentioning that there is no official tobacco control policy specifically targeting adolescents in Sudan [15]. The burden of tobacco use, morbidity and mortality will increase unless effective control and prevention programmes are developed and implemented in the near future [16]. These prevention programmes should target adolescents who are at high risk of tobacco use. The current study aims to identify the determinant factors of smokeless tobacco use and also to estimate the prevalence among adolescents.

\section{Methods}

The state of Khartoum is divided into three cities which includes seven localities according to administrative divisions. All seven localities were considered as strata and were included in the study. Moreover, schools in the localities were divided into strata according to the type of schools (public and private) and gender (boys and girls). This division produced four strata of schools; 216 public boys schools, 206 public girls schools, 264 private boys schools and 357 private girls schools. Consequently, from each stratum in each locality, one school was selected through a simple random sampling. As a result, 28 schools were selected for the study. However, a girls school in Omdurman locality was found to have an insufficient number of students, hence, another girls 
school from the same locality was added to fulfil the number needed for the sample size. Thus, a total of 29 schools participated in the study. At the school level, classes were divided into three strata according to grades (1st grade, 2nd grade, 3rd grade). In every participating school, a class was selected by simple random sampling from each grade. Through universal sampling, all students in the selected classes were targeted to participate in the study. Supplementary file 1.

The sample size of this study was calculated with open source epidemiological statistics for public health version 3.01 OpenEpi, Population size 205,319, anticipated frequency (p) $13.1 \%$ [17], absolute precision (d) 3\%, design effect (deff) 3. According to OpenEpi, 1455 participants were needed. However, the state has a large, diverse population, thus it is a heterogeneous community. Therefore, the number of participants needed was doubled. Moreover, the sample size was increased by $15 \%$ to overcome nonresponse. Consequently, the number of participants needed for the study was set to 3304 students.

After sampling, the number of participants from each locality was ensured to be in proportion to the size of the locality. Hence, localities with larger population had more students in the study than the smaller ones. Eventually, 3387 students participated in the study.

\section{Outcome and determinants}

The primary outcome 'has ever used toombak' was defined as the participant having used toombak, even if it was one dip, at any time prior to the study meanwhile if a participant had used toombak in the past 30 days, they were considered as 'current toombak user'. Data on the following socio-demographic characteristics were obtained from participants: age, gender, grade, academic performance, daily allowance (pocket money), type of school, location of the school, locality, family structure, and parents' education level. The determinants of toombak use consisted of exposure to second-hand smoke, pro and anti-tobacco messages, parents smoking cigarette, friends smoking cigarettes and using smokeless tobacco, teachers smoking cigarettes and using smokeless tobacco, self-efficacy and restriction of selling toombak to minors. As for the outcome for ever used toombak, the question was: Have you ever tried or experimented using toombak, even once? Yes/No.

\section{Data collection}

The study was granted ethical approval from the Medical Ethical Committee at the University Malaya Medical Center in September 2015 (MECID.NO: 20159-1666). In September 2016, the study received approval from the National Research Ethics Review Committee in the Federal Ministry of Health, Sudan. Subsequently, approval from the Ministry of Education in Khartoum State was obtained to carry out the study in the schools in the state. The aim and objectives of the study were explained to the schools' principals. Written consents for participating students were obtained from parents and students, after explaining the objectives of the study and ensuring confidentiality to the students.

Within 2 months, from September to October 2016, standard anonymous self-administered questionnaires were distributed to collect data from the students in the classroom by a member of the survey team without the presence of school personnel in the classroom. A validated Arabic version of the Global Youth Tobacco Survey questionnaire was adopted to be utilised in the study [18]. The Global Youth Tobacco Survey (GYTS) is an anonymous, self-administered, standardized, schoolbased survey of students designed to collects data on tobacco use among young people to monitor and guide the implementation and evaluation of tobacco prevention and control programmes [18]. The GYTS questionnaire included all the objectives of the study. Furthermore, it has been used in many previous studies in Sudan; hence, it will facilitate the comparison. The questionnaire was consisted of 76 questions, all of which were close-ended except for two. The questionnaire was designed to prevent students from skipping questions. The completion of the questionnaire by the participants took approximately 30 to $40 \mathrm{~min}$. The questionnaire was pre-tested in 19 students and adjusted accordingly. Those who participated in the pre-test were excluded from the main study.

\section{Data analysis}

IBM Statistics Package for the Social Sciences (SPSS) version 20 was used to analyse the data. Due to the use of multistage sampling method in the sampling process, a complex sample analysis was performed in analysis. Moreover, the weight of each participant was calculated and utilized accordingly. At first, the schools weight was calculated proportionally to the number of schools in the locality and afterword, the class weight was determined in ratio to the number of classes in the school. Descriptive statistics of the sociodemographic characteristics of the participants were given in terms of frequencies and percentages. To elicit the determinants that may contribute to toombak usage, a model was developed. Using univariate analysis, sociodemographic characteristics and other associated factors were obtained through complex samples General Linear Model. $P$-value was set to 0.25 because using $p$-value of 0.05 is very strict and might not identify important variables [19]. All variables above 0.25 were excluded. The univariate analysis for sociodemographic characteristics and for other associated factors was done for each group 
separately. Subsequently, significant sociodemographic characteristics and other associated factors from the above univariate analysis with $p$-value less than 0.25 were selected to undertake complex samples multivariate logistic regression for each group separately and at this step the $p$-value was set to 0.05 . The crude model was obtained from this step. Following that, the significant sociodemographic characteristics and other associated factors form the previous logistic regression was combined together to process under multivariate logistic regression. Step-by-step backward selection was used in multivariate logistic regression. Consequently, this produces the adjusted model for the study. The result was expressed in odds ratio (OR) with a 95\% confidence interval $(\mathrm{CI})$ and the $p$-value was considered significant if it was less than 0.05 .

\section{Results}

The response rate of the study was $100 \%$ for schools and students. Female students accounted for $57.3 \%$ of students while males accounted for $42.7 \%$. Students from public schools were $51.6 \%$ whereas $48.4 \%$ were from private schools. The overall of students who participated in the study were 3387 (Table 1). Overall, $78.2 \%$ of the students were living with both parents and only $1.1 \%$ of the students were enrolled in rural schools. Mean daily allowance was 8.8 Sudanese pounds, 95\% CI (8.57-9.04) and the standard error was 0.119 .

The overall prevalence of those who had ever used smokeless tobacco (toombak) was 7.6\%. Among male students, the prevalence was $11.0 \%$ while it was $5.0 \%$ in female students.

Only city, gender and family structure were the associated sociodemographic factors with those how had ever used smokeless tobacco. Concerning other determinant factors; exposure to second-hand smoke at home, friends smoking, receiving free smokeless tobacco, low selfefficacy and lack of restriction of selling tobacco to minors were associated with smokeless tobacco use in students. Living in Bahri city was a determinant of ever use of smokeless tobacco with (OR 1.58 CI 95\% 1.11-2.25) (Table 2). Male gender was also a significant determinant (OR 1.53 95\% CI 1.03-2.28). Living with one parent or others was a determinant (OR 1.52 95\% CI 1.032.23). Being in the third grade was a determinant for smokeless tobacco use; however, after adjustment, it turned out to be insignificant. Moreover, exposure to second-hand smoke at home was associated with smokeless tobacco use (OR 1.60 95\% CI 1.11-2.31). Friends smoking cigarettes was also a significant determinant for smokeless tobacco use (OR 1.78 95\% CI 1.22-2.60). A strong determinant was low self-efficacy (OR 7.47 95\% CI 4.45-12.52). Receiving free smokeless tobacco was also associated with smokeless tobacco use in students
(OR 2.12 95\% CI 1.20-3.72). Lack of restriction of selling smokeless tobacco to minors was another factor associated with ever using smokeless tobacco with (OR 1.73 95\% CI 1.25-2.39).

\section{Discussion}

El-Amin study found that the percentage for ever used toombak was $8.1 \%$ in 2005 [15]. This increased in 2014 GYTS to reach $13.2 \%$ [7]. However, it declined in Almahdi study to reach $10.9 \%$ [8]. Moreover, it further dropped in this study to reach $7.6 \%$. The current study had almost $99 \%$ of students from urban schools. Therefore, this might affect the prevalence of ever using toombak in this study since the use of smokeless tobacco is more prevalent among rural students [20]. The percentage of students who had ever used smokeless tobacco accounted for $11.2 \%$ in Egypt [21], 9\% in Kenya, 12.5\% in India, $16.2 \%$ in Nepal and $11.9 \%$ in Norway [8]. It seems that Sudan had the lowest rates among all the countries which have similar smokeless tobacco products as Sudan.

According to this study, males were more likely to have tried smokeless tobacco and it was statistically significant. Another study in Sudan demonstrated the same result when it reported that ever and current usage of smokeless tobacco were associated with the male gender among school students [15]. Moreover, in Saudi Arabia, a study found that users of smokeless tobacco were only males [22]. Despite the affordability of toombak and the ability to use it secretively without a trace of smoking smell in clothes, females usually avoid the use of smokeless tobacco in the Middle East region because it is labelled by communities as a masculine feature. A similar significant gender difference was also reported in a study in Swedish adolescents [9]. However, in a South African study, there was no gender difference in the current users of smokeless tobacco [20] because smokeless tobacco in South Africa was considered as women's choice of tobacco [23].

The present study showed that not living with both parents was associated with ever toombak use. This was compatible with a study among ninth grade students in USA when it reported that ever smokeless tobacco use was associated with living with one parent [24]. The difficulties to provide continuous supervision and discipline $[25,26]$ in the absence of one or both parents in the family may have contributed to tobacco use [27]. It seems that experimenting with tobacco use was associated with not living with both the father and the mother, however, the decision to continue using tobacco is determined by other factors [24].

In this study, the grade level had no significant relation to ever smokeless tobacco use and moreover, there was no age difference in those had ever used smokeless 
Table 1 Sociodemographic characteristics of participants

\begin{tabular}{|c|c|c|c|}
\hline Characteristics & Unweighted Counts & Weighted Percentage \% & $95 \% \mathrm{Cl}$ \\
\hline \multicolumn{4}{|l|}{ Locality } \\
\hline Khartoum & 422 & $17.9 \%$ & $16.4-19.5$ \\
\hline Jabal Awliya & 518 & $14.0 \%$ & $12.9-15.2$ \\
\hline Omdurman & 459 & $12.5 \%$ & $11.5-13.6$ \\
\hline Karari & 442 & $11.2 \%$ & $10.2-12.2$ \\
\hline Ombada & 647 & $17.2 \%$ & $16.0-18.4$ \\
\hline Bahri & 375 & $10.1 \%$ & $9.2-11.1$ \\
\hline East Nile & 511 & $17.2 \%$ & 15.9-18.6 \\
\hline Missing & - & & \\
\hline \multicolumn{4}{|l|}{ Location of school } \\
\hline Urban & 3266 & $98.9 \%$ & $98.5-99.2$ \\
\hline Rural & 108 & $1.1 \%$ & $0.9-1.3$ \\
\hline Missing & - & & \\
\hline \multicolumn{4}{|l|}{ Type of School } \\
\hline Public & 2035 & $51.6 \%$ & $50.0-53.2$ \\
\hline Private & 1339 & $48.4 \%$ & $46.6-50.3$ \\
\hline Missing & - & & \\
\hline \multicolumn{4}{|l|}{ Age } \\
\hline 14 years or less & 726 & $21.8 \%$ & $20.4-23.2$ \\
\hline 15 years & 879 & $24.8 \%$ & $23.4-26.3$ \\
\hline 16 years & 964 & $28.6 \%$ & $27.1-30.2$ \\
\hline 17 years above & 783 & $24.8 \%$ & $23.3-26.3$ \\
\hline Missing & 22 & & \\
\hline \multicolumn{4}{|l|}{ Daily Allowance } \\
\hline Low $\leq 5$ & 1240 & $35.7 \%$ & $34.1-37.3$ \\
\hline Average 6-10 & 1461 & $48.8 \%$ & $47.0-50.6$ \\
\hline Above Average 11-15 & 245 & $9.7 \%$ & $8.6-10.9$ \\
\hline High 16-20 & 107 & $4.7 \%$ & $3.9-5.6$ \\
\hline Very High 21-50 & 19 & $1.0 \%$ & $0.6-1.6$ \\
\hline Missing & 302 & & \\
\hline \multicolumn{4}{|l|}{ Gender } \\
\hline Male & 1604 & $42.7 \%$ & $41.1-44.3$ \\
\hline Female & 1770 & $57.3 \%$ & $55.5-59.0$ \\
\hline Missing & - & & \\
\hline \multicolumn{4}{|l|}{ Grade } \\
\hline 1st secondary & 1098 & $31.2 \%$ & $29.9-33.0$ \\
\hline 2nd secondary & 953 & $23.5 \%$ & $22.2-24.8$ \\
\hline 3rd secondary & 1323 & $45.3 \%$ & $43.5-47.1$ \\
\hline Missing & - & & \\
\hline \multicolumn{4}{|l|}{ Academic Performance } \\
\hline Excellent & 615 & $20.3 \%$ & $18.9-21.8$ \\
\hline Very good & 1430 & $44.1 \%$ & $42.4-45.8$ \\
\hline Good & 1064 & $29.7 \%$ & $28.2-31.2$ \\
\hline Fair & 160 & $4.6 \%$ & $4.0-5.3$ \\
\hline
\end{tabular}


Table 1 Sociodemographic characteristics of participants (Continued)

\begin{tabular}{|c|c|c|c|}
\hline Characteristics & Unweighted Counts & Weighted Percentage \% & $95 \% \mathrm{Cl}$ \\
\hline Poor & 42 & $1.3 \%$ & $1.0-1.8$ \\
\hline Missing & 63 & & \\
\hline \multicolumn{4}{|l|}{ Family structure } \\
\hline Father only & 74 & $1.8 \%$ & $1.4-2.3$ \\
\hline Mother Only & 374 & $11.0 \%$ & $10.0-12.1$ \\
\hline Father and Mother & 2616 & $78.2 \%$ & $76.8-79.6$ \\
\hline Other & 294 & $9.0 \%$ & $8.1-10.0$ \\
\hline Missing & 16 & & \\
\hline \multicolumn{4}{|c|}{ Father's level of education } \\
\hline Illiterate & 140 & $3.7 \%$ & $3.1-4.4$ \\
\hline Can read and write & 470 & $12.7 \%$ & $11.7-13.8$ \\
\hline Primary & 210 & $5.8 \%$ & $5.1-6.6$ \\
\hline Elementary & 296 & $8.6 \%$ & $7.7-9.6$ \\
\hline Secondary & 538 & $15.2 \%$ & $14.1-16.4$ \\
\hline University & 665 & $21.3 \%$ & $19.9-22.8$ \\
\hline Higher Education & 333 & $12.4 \%$ & $11.2-13.7$ \\
\hline Do not know & 694 & $20.4 \%$ & $19.1-21.8$ \\
\hline Missing & 28 & & \\
\hline \multicolumn{4}{|c|}{ Mother's level of education } \\
\hline Illiterate & 290 & $8.0 \%$ & $7.2-8.9$ \\
\hline Can read and write & 375 & $10.4 \%$ & $9.4-11.4$ \\
\hline Primary & 334 & $9.4 \%$ & $8.5-10.5$ \\
\hline Elementary & 392 & $11.6 \%$ & $10.6-12.7$ \\
\hline Secondary & 666 & $19.5 \%$ & $18.2-20.9$ \\
\hline University & 573 & $19.4 \%$ & 18.0-20.9 \\
\hline Higher Education & 173 & $5.9 \%$ & $5.1-6.8$ \\
\hline Do not know & 543 & $15.9 \%$ & $14.7-17.2$ \\
\hline Missing & 28 & & \\
\hline
\end{tabular}

tobacco in this study. A similar result also was noticed in a study in Congo which found that there was no significant association between current smokeless tobacco use and age [28]. The age range in secondary schools is too narrow to detect any difference. The differences might be apparent if comparison was made between students in secondary stage of schooling to primary stage of schooling [29]. Hence, the result of lack of association between grade, age and toombak use might be due to the narrow age range in the study, 14-18-year-olds. Nonetheless, the finding of the study might be authentic. Additionally, the present study showed no significant difference between urban and rural school students regarding their use of smokeless tobacco. The lack of association in the study can be due to under-representation of rural students. The finding of the study did not show any significant difference between public and private schools in those who had ever used smokeless tobacco.
This might be clarified by the closeness of tobacco regulations and the similitude in students in public and private schools [29].

Many factors influence the academic performance of students besides tobacco use such as, interest in school and classroom environment, parental support, past achievement, academic motivation [30]. On the other hand, multiple factors determine tobacco use in students other than academic performance. Therefore, this may explain the lack of association between academic performance and smokeless tobacco use in the present study.

This study showed no significant association of daily allowance with having ever used smokeless tobacco. In Sudan, smokeless tobacco is planted, manufactured and produced locally, thus it is cheap and affordable. The cheap price of toombak, low taxation of tobacco products and the sharing nature of smokeless tobacco use in 
Table 2 Crude and adjusted models for Independent variables for ever used toombak

\begin{tabular}{|c|c|c|c|c|c|c|c|}
\hline \multirow[t]{2}{*}{ Variable } & \multirow{2}{*}{$\begin{array}{l}\text { Total } \\
\mathbf{n}\end{array}$} & \multirow{2}{*}{$\begin{array}{l}\text { Ever } \\
\text { used } \\
\text { toombak }\end{array}$} & \multirow{2}{*}{$\begin{array}{l}\text { Never } \\
\text { used } \\
\text { toombak }\end{array}$} & \multicolumn{2}{|c|}{ Crude OR (univariate) } & \multicolumn{2}{|c|}{ Adjusted OR (multivariate) } \\
\hline & & & & OR Cl 95\% & $P$-value & OR Cl 95\% & $P$-value \\
\hline \multicolumn{8}{|l|}{ City } \\
\hline Khartoum & 926 & $63(2)$ & $863(29.9)$ & $1.08(0.73-1.61)$ & $<0.003$ & $1.08(0.70-1.67)$ & $<0.034$ \\
\hline Omdurman & 1526 & $111(3)$ & 1415 (37.8) & Ref & & Ref & \\
\hline Bahri & 873 & $98(2.5)$ & $775(24.7)$ & $1.82(1.27-2.63)$ & & $1.58(1.11-2.25)$ & \\
\hline \multicolumn{8}{|l|}{ Gender } \\
\hline Male & 1576 & $189(4.7)$ & $1387(37.9)$ & $2.30(1.65-3.22)$ & $<0.001$ & $1.53(1.03-2.28)$ & $<0.032$ \\
\hline Female & 1749 & $83(2.9)$ & $1666(54.5)$ & Ref & & Ref & \\
\hline \multicolumn{8}{|l|}{ Grade } \\
\hline Ist & 1081 & $64(1.6)$ & $1017(29.6)$ & Ref & $<0.024$ & Ref & $<0.232$ \\
\hline 2nd & 942 & $75(1.9)$ & $867(21.6)$ & $1.49(0.99-2.24)$ & & $1.29(0.83-2.00)$ & \\
\hline $3 r d$ & 1302 & $133(4.1)$ & $1169(41.3)$ & $1.66(1.14-2.41)$ & & $1.40(0.94-2.08)$ & \\
\hline \multicolumn{8}{|l|}{ Family structure } \\
\hline Father and mother & 2576 & $198(5.3)$ & $2378(72.9)$ & Ref & $<0.010$ & Ref & $<0.032$ \\
\hline Others & 733 & $74(2.3)$ & $659(19.5)$ & $1.60(1.11-2.30)$ & & $1.52(1.03-2.23)$ & \\
\hline \multicolumn{8}{|c|}{ Exposure to second-hand smoke at home } \\
\hline Yes & 807 & $106(2.9)$ & $701(21.2)$ & $1.60(1.06-2.42)$ & $<0.024$ & $1.60(1.11-2.31)$ & $<0.010$ \\
\hline No & 2506 & $166(4.7)$ & $2340(71.3)$ & Ref & & Ref & \\
\hline \multicolumn{8}{|c|}{ Seeing someone smoke in school } \\
\hline Yes & 673 & $101(2.7)$ & $572(17.9)$ & $1.46(1.01-2.11)$ & $<0.041$ & $1.40(0.97-2.02)$ & $<0.065$ \\
\hline No & 2632 & $170(4.9)$ & $2462(74.5)$ & Ref & & Ref & \\
\hline \multicolumn{8}{|c|}{ Friends smoking cigarette } \\
\hline Yes & 977 & $154(4.3)$ & $823(24.7)$ & $1.80(1.12-2.89)$ & $<0.014$ & $1.78(1.22-2.60)$ & $<0.003$ \\
\hline No & 2334 & $117(3.3)$ & $2217(67.7)$ & Ref & & Ref & \\
\hline \multicolumn{8}{|c|}{ Restriction of selling toombak to minors } \\
\hline Yes & 93 & $14(0.4)$ & $79(2.1)$ & $1.12(0.34-3.73)$ & $<0.015$ & $1.20(0.39-3.71)$ & $<0.004$ \\
\hline No & 903 & $107(2.9)$ & $796(23.3)$ & $1.63(1.17-2.28)$ & & $1.73(1.25-2.39)$ & \\
\hline I did not try to buy & 2240 & $140(4.2)$ & $2100(67.1)$ & Ref & & Ref & \\
\hline \multicolumn{8}{|c|}{ Received free toombak from companies } \\
\hline Yes & 179 & $45(1.2)$ & $134(3.5)$ & $2.26(1.26-4.07)$ & $<0.006$ & $2.12(1.20-3.72)$ & $<0.009$ \\
\hline No & 3056 & $217(6.3)$ & $2839(89)$ & Ref & & Ref & \\
\hline \multicolumn{8}{|c|}{ Low self-efficacy (Peer pressure for using toombak) } \\
\hline Yes & 116 & $63(1.5)$ & $53(1.6)$ & $7.32(4.25-12.62)$ & $<0.001$ & $7.47(4.45-12.52)$ & $<0.001$ \\
\hline No & 3145 & $200(6)$ & 2945 (90.9) & Ref & & Ref & \\
\hline
\end{tabular}

society might diminish the association between smokeless tobacco use and daily allowance [29].

Our study showed no significant association between parents' level of education with having ever used smokeless tobacco. This finding was in agreement with another study in Sudan which showed the lack of association between parents' level of education and ever using smokeless tobacco among secondary school students [8]. Tobacco use in adolescent is unacceptable in Sudanese community and parents oppose this behaviour irrespective of their level of education.
Exposure to second-hand smoke increases the sensitivity to nicotine and leads to the desire for nicotine use. Moreover, exposure to second-hand smoke in adolescents normalises the behaviour of using tobacco and puts a social pressure on adolescents to use tobacco to conform with their surroundings [31, 32]. These may explain the association between second-hand smoke at home and ever using smokeless tobacco.

Selling tobacco to minors was associated with having tried smokeless tobacco in the current study. Although selling tobacco to minors is prohibited in Sudan, many 
adolescents succeed in buying tobacco with the excuse that it is bought for an adult person. It is prevalent to send minors to buy tobacco for adults in Africa [33]. Sending minors to buy tobacco for adults was a risk factor for initiation of tobacco use in Nigeria and Gambia [33, 34].

The promotion of smokeless tobacco was associated with ever using smokeless tobacco among adolescents in the present study. This result was compatible with a finding from Congo-Brazzaville; when a study reported that pro-tobacco advertising was associated with the current use of smokeless tobacco in students, aged 1217 years [28]. A systematic review of nine longitudinal studies from four countries conducted in 2003, concluded that exposure to tobacco advertising and promotion increases the likelihood of tobacco use in adolescents [35]. However, a study in Sudan showed that there was no significant association between tobacco advertising and intention to use smokeless tobacco [8].

Anti-tobacco advertising may counter the effect of pro-tobacco advertising but the outcome has not yet reached to the extent of decreasing the prevalence of tobacco use in adolescents [36]. Furthermore, not all antitobacco advertising campaigns have produced the desired effectiveness and impact. The ineffective antitobacco advertisement may have no effect on adolescents' tobacco prevention and even more, it may produce an unintended effect. This may interpret the lack of association between anti-tobacco messages and ever using smokeless tobacco in this study.

The inability to reject smokeless tobacco when it was offered by a friend was associated with having tried smokeless tobacco in adolescents in the present study. This was compatible with a Bangladeshi study among rural secondary school students which established the association between low self-efficacy and smokeless tobacco use [37]. Low selfefficacy among adolescents may exhibit a favourable social and emotion perception about tobacco use [38].

El-Amin study in Sudan as well as this study have documented the lack of association between parents smoking and the use of smokeless tobacco in students [15]. The type of tobacco used by parents has an effect on the tobacco product used by adolescents. This was evident in studies from Sudan and Sweden [15, 39]. Both studies have shown no significant association between parents smoking cigarettes and smokeless tobacco use in adolescents; however, the smokeless tobacco use in parents was associated with current use of smokeless tobacco in adolescents [15, 39]. Moreover, El-Amin study reported that cigarette smoking among friends was positively associated with ever using smokeless tobacco among adolescents in Sudan [15]. The same result was documented in the current study. Adolescents might imitate the behaviour of their peers; however, in other cases, they might choose friends who had the same behaviour [40].
In this study, tobacco use in teachers was not associated with adolescents having tried smokeless tobacco. Older adolescents might not consider teachers as role models; therefore, they might not copy and imitate the behaviour of teachers. On the other hand, peers and friends might be more influential [41].

\section{Strengths and limitations}

The novelty of current study is that it addresses the issues of smokeless tobacco in large sample size with high participation rate. Moreover; it addresses its association with family structure, allowance, grade, academic performance, location of school and type of school. In addition to exposure to second hand-smoke, selling tobacco to minors, low self-efficacy, pro and anti-tobacco messages, friends using tobacco, parents using tobacco and teacher using tobacco. The results of study can extrapolate through the state and moreover to the Sudan. On the other hand, the study targeted students only; therefore, it cannot be generalised to school drop-outs. Furthermore, the under representation of rural school students might obscure their characteristics and determinants; therefore, further study among these students is recommended. Moreover, addressing the issues of smokeless tobacco use in parents and tobacco use in siblings might have added more detailed information which could not be obtained from this study. At last, this is a cross-sectional study; thus, no causal relationship can be obtained from this study.

\section{Conclusion}

The study can help spot high risk groups of adolescents through the identification of the determinant factors of using smokeless tobacco. Moreover, it can help design and develop prevention programmes that counter the determinant factors. Low self-efficacy is the greatest determinant of smokeless tobacco use in adolescents which increases smokeless tobaccos usage by seven folds; therefore, the prevention programmes should target and enhance self-efficacy of adolescents. The effect of the promotion of smokeless tobacco and selling tobacco to minors should be taken into consideration since it points to the lack of enforcement, efficacy of prohibition of tobacco promotion and restriction of selling tobacco to minors. Augmentation and reinforcement of legislations that prohibit promotion of tobacco and restrict selling tobacco to minors is fundamental in tobacco prevention. Further research is needed to investigate on rural students and drop-outs from schools in addition to monitoring the trend of smokeless tobacco use.

Abbreviations

Cl: Confidence interval; GYTS: Global Youth Tobacco Survey; OR: Odd ratio 


\section{Supplementary Information}

The online version contains supplementary material available at https://doi. org/10.1186/s13690-021-00699-w.

\section{Additional file 1.}

\section{Acknowledgements}

The authors would like to express the gratitude to Federal Ministry of Health, Khartoum, Sudan, and Ministries of Health and Education in Khartoum State for providing the data and support for this research.

Dr. Khalid Elmardi: Former Director, Health Information, Research and Evidence Administration. Federal Ministry of Health, Khartoum, Sudan. Dr. Zaher Elsiddiq: Former Director of Non Communicable Diseases Department.Khartoum State Ministry of Health, Khartoum, Sudan. Dr. Imad Abdulmajeed: NGHA, Riyadh, Saudi Arabia.

\section{Authors' contributions}

MO: Substantial contributions to the conception and design of the work and the acquisition, analysis, interpretation of data for the work. Drafting the work and revising it critically for important intellectual content. Final approval of the version to be published. Agreement to be accountable for all aspects of the work in ensuring that questions related to the accuracy or integrity of any part of the work are appropriately investigated and resolved. NDNF: Substantial contributions to the conception and design of the work, analysis and interpretation of data for the work. Revising the work critically for important intellectual content. Final approval of the version to be published. Agreement to be accountable for all aspects of the work in ensuring that questions related to the accuracy or integrity of any part of the work are appropriately investigated and resolved. NA: Substantial contributions to the conception and design of the work, analysis and interpretation of data for the work. Revising the work critically for important intellectual content. Final approval of the version to be published. Agreement to be accountable for all aspects of the work in ensuring that questions related to the accuracy or integrity of any part of the work are appropriately investigated and resolved. MD: Substantial contributions analysis and interpretation of data for the work. Final approval of the version to be published. Agreement to be accountable for all aspects of the work in ensuring that questions related to the accuracy or integrity of any part of the work are appropriately investigated and resolved.

\section{Funding}

This research did not receive any specific grant from funding agencies in the public, commercial, or not-for-profit sectors.

\section{Availability of data and materials}

The data that support the findings of this study are available from Ministries of Health and Education in Sudan. However, restrictions apply to the availability of these data, which were used under license for the current study, and so are not publicly available. Data are however available from the authors upon reasonable request and with permission of Ministries of Health and Education in Sudan.

\section{Declarations}

\section{Ethics approval and consent to participate}

- Medical Ethics committee University Malaya Medical center,

MECID.NO: 20159-1666, 19-10-2015

- National Health Research Ethics Committee, Federal Ministry of Health, Sudan

07-09-2016

Informed consent was obtained from the participants and their parents or guardians after they were informed about the aim and objectives of the study; furthermore, they were informed that participation is optional and voluntary.

\section{Consent for publication}

Not applicable.

\section{Competing interests}

The authors declare that they have no competing interests.

\section{Author details}

'Department of Social and Preventive Medicine, Faculty of Medicine, University of Malaya, Kuala Lumpur, Malaysia. ${ }^{2}$ Centre for Epidemiology and Evidence-Based Practice, Department of social and Preventive Medicine, Faculty of Medicine, University of Malaya, 50603 Kuala Lumpur, Malaysia.

Received: 15 April 2021 Accepted: 27 September 2021

Published online: 12 October 2021

\section{References}

1. WHO I. Smokeless tobacco and some tobacco-specific N-nitrosamines. IARC Monogr Eval Carcinog Risks Hum. 2007:89:1-592.

2. Idris AM, Ibrahim YE, Warnakulasuriya KAAS, Cooper DJ, Johnson NW, Nilsen R. Toombak use and cigarette smoking in the Sudan: estimates of prevalence in the Nile state. Prev Med. 1998;27(4):597-603.

3. Idris AM, Ibrahim SO, Vasstrand EN, Johannessen AC, Lillehaug JR, Magnusson B, et al. The Swedish snus and the Sudanese toombak: are they different? Oral Oncol. 1998;34(6):558-66.

4. Dobbs MR. Clinical Neurotoxicology E-book: syndromes, Substances, Environments: Elsevier Health Sciences; 2009.

5. Ahmed H, Mahgoob R. Impact of Toombak dipping in the etiology of oral cancer: Gender-exclusive hazard in the Sudan. J Cancer Res Ther. 2007;3(2): $127-30$.

6. Ahmed HG. Aetiology of Oral Cancer in the Sudan. J Oral Maxillofacial Res. 2013;4(2):e3.

7. World Health Organization. Global Youth Tobacco Survey Fact Sheets and Country Reports. 2014.

8. Almahdi HM, Ali RW, Nasir EF, Astrom AN. Socio-cognitive correlates of intention to use Toombak: a cross-sectional study among students (13-16 years) in Khartoum state, Sudan. BMC Public Health. 2017;18(1):88.

9. Galanti MR, Rosendahl I, Wickholm S. The development of tobacco use in adolescence among "snus starters" and "cigarette starters": an analysis of the Swedish "BROMS" cohort. Nicotine Tob Res. 2008;10(2):315-23.

10. Hussain A, Zaheer S, KJBph S. Individual, social and environmental determinants of smokeless tobacco and betel quid use amongst adolescents of Karachi: a school-based cross-sectional survey. BMC Public Health. 2017;17:913.

11. Reddy KS, Perry CL, Stigler MH, MJTL A. Differences in tobacco use among young people in urban India by sex, socioeconomic status, age, and school grade: assessment of baseline survey data. Lancet. 2006;367(9510):589-94.

12. Page RM, Danielson M. Multi-country, cross-national comparison of youth tobacco use: findings from global school-based health surveys. Addict Behav. 2011;36(5):470-8.

13. Population Census Council. 5th Sudan population and housing census 2008 - Priority results. Sudan Central Bureau of Statistics; 20092009.

14. World Health Organization. WHO report on the global tobacco epidemic, 2017: monitoring tobacco use and prevention policies: World Health Organization; 2017.

15. El-Amin SE-T, Nwaru BI, Ginawi I, Pisani P, Hakama M. The role of parents, friends and teachers in adolescents' cigarette smoking and tombak dipping in Sudan. Tob Control. 2010:tc. 2010:038091.

16. Warren CW, Jones NR, Peruga A, Chauvin J, Baptiste J-P, dSV C, et al. Global youth tobacco surveillance, 2000-2007. Morb Mortality Weekly Rep Surveill Summ (Washington, DC: 2002). 2008;57(1):1-28.

17. Atari DO. Gender differences in the prevalence and determinants of tobacco use among school-aged adolescents (11-17 years) in Sudan and South Sudan. Pan Afr Med J. 2014;18:118.

18. Global Youth Tobacco Survey Collaborative Group. Global Youth Tobacco Survey (GYTS): Core Questionnaire with Optional Questions, Version 1.0. 2012.

19. Mickey RM, Greenland S. The impact of confounder selection criteria on effect estimation. Am J Epidemiol. 1989;129(1):125-37.

20. Reddy PS, James S, Resnicow K, Sewpaul R, Masuka P, van den Borne B. Prevalence and correlates of smokeless tobacco use among grade 8-11 school students in South Africa: a Nationwide study. Nicotine Tob Res. 2014; 16(9):1167-73.

21. World Health Organization E. Global Youth Tobacco survey. 2014. 
22. Al Agili DE, Park HK. The prevalence and determinants of tobacco use among adolescents in Saudi Arabia. J Sch Health. 2012;82(3):131-8.

23. Keith H, Kathryn O, Priya K, Rashidah W. Oral and Systemic Effects of Smokeless Tobacco from the African, Asian, Latin American, European, and Middle Eastern Regions. Journal of Dental and Oral Health. 2017;6:2.

24. Murray DM, Roche LM, Goldman Al, Whitbeck J. Smokeless tobacco use among ninth graders in a north-central metropolitan population: crosssectional and prospective associations with age, gender, race, family structure, and other drug use. Prev Med. 1988;17(4):449-60.

25. El Hassan Al Awad AM, EJJCD S-B. Childhood problems in a Sudanese city: A comparison of extended and nuclear families. Child Development. 1992; 63(4):906-14.

26. Wagner KD, Ritt-Olson A, Soto DW, Unger JB. Variation in family structure among urban adolescents and its effects on drug use. Subst Use Misuse. 2008;43(7):936-51.

27. Georgiades K, Boyle MH, Duku E, Racine Y. Tobacco use among immigrant and nonimmigrant adolescents: individual and family level influences. J Adolesc Health. 2006;38(4):443.e1-7.

28. Rudatsikira E, Muula AS, Siziya S. Current use of smokeless tobacco among adolescents in the republic of Congo. BMC Public Health. 2010;10:16.

29. Othman M, Aghamohammadi N, Nik Farid ND. Determinants of shisha use among secondary school students in Sudan. BMC Public Health. 2019;19(1): 1390.

30. Cox RG, Zhang L, Johnson WD, Bender DR. Academic performance and substance use: findings from a state survey of public high school students. J Sch Health. 2007;77(3):109-15.

31. Xi B, Liang Y, Liu Y, Yan Y, Zhao M, Ma C, et al. Tobacco use and secondhand smoke exposure in young adolescents aged 12-15 years: data from 68 low-income and middle-income countries. Lancet Glob Health. 2016;4(11): e795-805.

32. McGrath JJ, Racicot S, Okoli CTC, Hammond SK, O'Loughlin J. Airborne nicotine, secondhand smoke, and precursors to adolescent smoking. Pediatrics. 2018;141(Suppl 1):S63-s74.

33. Odukoya OO, Odeyemi KA, Oyeyemi AS, Upadhyay RP. Determinants of smoking initiation and susceptibility to future smoking among school-going adolescents in Lagos state, Nigeria. Asian Pac J Cancer Prev. 2013;14(3): 1747-53.

34. Jallow IK, Britton J, Langley T. Prevalence and Determinants of Susceptibility to Tobacco Smoking Among Students in The Gambia. Nicotine \& Tobacco Research. 2019;21(8):1113-21.

35. Lovato C, Linn G, Stead LF, Best A. Impact of tobacco advertising and promotion on increasing adolescent smoking behaviours. Cochrane Database Syst Rev. 2003;4:Cd003439.

36. Unger JB, Cruz TB, Schuster D, Flora JA, Johnson CA. Measuring exposure to pro- and anti-tobacco marketing among adolescents: intercorrelations among measures and associations with smoking status. J Health Commun. 2001;6(1):11-29.

37. Ullah MZ, Lim JN, Ha M-A, Rahman MM. Smokeless tobacco use: pattern of use, knowledge and perceptions among rural Bangladeshi adolescents. PeerJ. 2018;6:e5463-e.

38. Sterling KL, Diamond PM, Mullen PD, Pallonen U, Ford KH, McAlister AL. Smoking-related self-efficacy, beliefs, and intention: assessing factorial validity and structural relationships in 9 (th)-12(th) grade current smokers in Texas. Addict Behav. 2007;32(9):1863-76.

39. Rosendahl Kl, Galanti MR, Gilljam H, Ahlbom A. Smoking mothers and snuffing fathers: behavioural influences on youth tobacco use in a Swedish cohort. Tob Control. 2003;12(1):74-8.

40. Simons-Morton B, Farhat T. Recent findings on peer group influences on adolescent substance use. J Prim Prev. 2010;31(4):191-208.

41. Wiium N, Torsheim T, Wold B. Normative processes and adolescents' smoking behaviour in Norway: a multilevel analysis. Soc Sci Med. 2006;62(7): 1810-8.

\section{Publisher's Note}

Springer Nature remains neutral with regard to jurisdictional claims in published maps and institutional affiliations.

\section{Ready to submit your research? Choose BMC and benefit from:}

- fast, convenient online submission

- thorough peer review by experienced researchers in your field

- rapid publication on acceptance

- support for research data, including large and complex data types

- gold Open Access which fosters wider collaboration and increased citations

- maximum visibility for your research: over $100 \mathrm{M}$ website views per year

At BMC, research is always in progress.

Learn more biomedcentral.com/submissions 